\title{
A study of material composition disclosure practices in green footwear products
}

\author{
Jocelise J. Jacques $^{\mathrm{a}^{*}}$ and Lia B. M. Guimarães ${ }^{\mathrm{b}}$ \\ ${ }^{a}$ Department of Design and Graphics, Federal University of Rio Grande do Sul, Av. Osvaldo Aranha 99 - S. 408 , \\ 90035-190, Porto Alegre, RS, Brazil \\ ${ }^{\mathrm{b}}$ Department of Industrial Engineering, Federal University of Rio Grande do Sul, Porto Alegre, RS, Brazil
}

\begin{abstract}
This work is based on the study of pioneering sustainable product development initiatives, and the analysis was guided by the cradle-to-cradle concept, which sees the waste of a given process as raw material for another, just like it happens in nature. Several studies on human factors have focused on factory conditions and workers dealing with product assembly. This research, however, relates more to consumer behavior, product use and end-of-life. The purchase of more environmentally-friendly products, in particular, is heavily influenced by the information made available by the companies. In this scenario, this article discusses three early but notable efforts on green product development, focusing on the disclosure practices adopted by the companies regarding the composition of their products. Research and data collection has focused on the footwear industry, whose products satisfy a basic human need and are ubiquitous worldwide. The use of hazardous materials and chemicals in shoe manufacturing, particularly the use of chromium - a highly toxic element - in addition to toxic solvents and adhesives and non-recyclable synthetic materials can pose serious risks to human health and the environment, even though the consumer usually is not aware of all the relevant characteristics of this kind of product.
\end{abstract}

Keywords: sustainable product development, sustainable production, footwear industry, green products.

\section{Introduction}

The main environmental concerns in the footwear industry are related to the processing and use of raw materials and components and to the end-of-life disposal of the products. The global production of footwear products has jumped from 2.5 billion pairs/year in 1950 to 20 billion pairs in 2010 , leading to a present average of about 3 pairs/year for every person on the planet (and as high as 8 pairs/person/year in some countries), which illustrates the magnitude of the challenge when dealing with the final disposal of footwear products $[1,2,3]$.

The discussion presented in this paper is part of a broad analysis from a perspective based on the cradle to cradle concept. According to this concept, products must be designed in such a way that, in the end of their service life, they can be reused without loss of quality (as technical nutrients) - technical metabolism- or returned to the environment as biological nutrients and safely decomposed - biological metabolism [4]. Waste generation, either in production or consumption, is the result of an inadequate design solution [5] that causes problems to society as a whole, especially when the public ends up incurring the costs (in an economic and environmental sense) of the final disposal of waste products.

The main areas of cradle to cradle concept are materials use and reutilization, water use, energy consumption and social responsibility [4]. Most initiatives do involve the main areas highlighted in the cradle to cradle approach- even though companies may follow different strategies to tackle the problems, with varying levels of implementation and results obtained.

The cradle to cradle concept is used in this study as a benchmark or basis to guide the analysis of ongoing and in some cases early sustainable product development initiatives. Naturally, the concept of mimicking current production systems in the cyclic

\footnotetext{
*Corresponding author. E-mail: jocelise.jacques@ufrgs.br.
} 
principle of nature represents a very ambitious longterm goal that must be sought in gradual improvements and advances, but it can be, nevertheless, a useful tool in guiding present and future actions.

This work presents background information on the evolution and present characteristics of the global footwear industry and discusses the disclosure information practices inside the sustainable product development initiatives.

The case studies presented here describe the material composition disclosure practices adopted by three American companies - Patagonia, Simple Shoes and Nike - which have worked on green product development initiatives for the last several years. Despite the looming challenges, some significant improvements have been made.

\section{Social responsibility according to the Cradle to Cradle concept}

Social responsibility is one of the key pillars of cradle to cradle design, together with materials selection, use and reutilization, use of water and energy consumption.

Typically social responsibility is related primarily to the company's practices regarding work conditions, related legislation and international standards of health and safety; and human factors oftentimes refer to the reality of workers in the workplace.

In the conventional cradle to grave logic, the development of products focuses only on end-users, or consumers. However, it should be noticed that there are several other users involved in the whole process, such as those who manufacture, transport, sell and repair products, as well as society at large - which can be considered an indirect user when affected by the production, use and disposal of products.

Therefore, in addition to taking into consideration the health and wellbeing of workers and communities involved in the production process, designers must also consider the persons who will buy and use the product, as well as those who will be involved in the take-back and reutilization or remanufacturing stages. Briefly, this requires understanding sustainability in a broad context and thinking about all the users involved in the process.

In this context, materials selection can be a particularly demanding process for designers. In addition to differentiating materials into recycled, renewable, recyclable and compostable (for future technical and biological metabolisms), it is fundamental to evaluate and rule out possible human health and environmental hazards through detailed chemical and toxicity analyses [4].

In summary, it can be said that, in the sustainable product development process, even if the focus remains mainly on the end-user, it is absolutely necessary to think of all users involved, particularly because the consumer should be aware of the whole life cycle and related environmental impact of the products being considered.

In this regard, companies must adopt and implement social and ethical performance goals in its whole supply chain, as well as make them publicly available. The Cradle to Cradle certification recommends, for instance, the adoption of the UN Global Compact model, a strategic policy initiative for businesses that are committed to aligning their operations and strategies with ten universally accepted principles in the areas of human rights, labor, environment and anti-corruption [6].

When evaluating social responsibility, the $\mathrm{C} 2 \mathrm{C}$ certification process endorses, and actually encourages, the adoption of specific third-party certifications such as those developed by Social Accountability International (SA 8000), the Fair Labor Association (FLA) or the Worldwide Responsible Accredited Production (WRAP). It is worth mentioning that the above organizations work with voluntary initiatives, and therefore the adoption of principles and the quest for excellence in work conditions is directly related to the companies' decisions and level of commitment.

In this study, in addition to the modern understanding of social responsibility, the importance of the precautionary principle will also be discussed, together with its possible use as an additional piece of evidence to assess a company's responsibility in its relationship with its clients, in particular, and society in general.

\subsection{Precautionary principle}

The precautionary principle concept was developed in the 1970's when scientists and policy makers were trying to deal with a phenomenon referred to as "the death of forests" and its possible causes, including air pollution and acid rain. One of the first pieces of legislation in which this concept appears is the German Clean Air Act, from 1974 [7].

The main element of the precautionary principle is the general rule of action in situations that could potentially cause irreversible damage to health or the 
environment. In other words, it is necessary to act to reduce the risk before there is substantial proof of damage. This kind of rule is used primarily in cases of public health. In this paper, we defend the idea that the precautionary principle should be broadly adopted in laws and regulations related to industrial production. In several cases, ample information about the potential risk of certain substances and industrial processes are widely known long before any type of regulation is finally proposed, and typically only after substantial damage to human health or the environment has been recorded [7].

A proactive approach can be embraced by companies when they implement a restricted-substance list banning materials known or suspected to be harmful. Such actions expand the traditional concept of social responsibility beyond the obligation the company has to its own workers, to include society at large both in the present and for future generations. In this work, social responsibility is understood in this broader manner.

\subsection{Information disclosure}

The insertion of the environmental dimension in the product development process is a departure from the deep-rooted paradigm in which humans dominate nature, transitioning to a new view where human activities are comprised in a natural collaborative cycle [8]. Considering the complexity of this transition, McDonough and Braungart [4] describe a list of five main stages that should be reached by the companies in this evolution into a new paradigm of product development.

The first and most basic stage refers to the elimination of substances widely recognized as hazardous from the products. The second stage, also considered fundamental, is directly related to the information disclosure practices adopted by the company. This second stage takes place when the company makes clear to its clients all the characteristics of the materials and processes used in the production of its products.

Although the information disclosure stage may seem simple, it is still not common practice, as we will discuss later in the case studies. Generally speaking, currently only very few companies actually make available a list of substances and/or materials used in their products. This happens for several reasons, and one of the most concerning reasons is that oftentimes not even the companies know exactly all substances used in their product, not to mention the general lack of knowledge regarding the environmental impact of the materials used [7].

The Cradle to Cradle concept has "materials" as one of its five main areas (in addition to reutilization, water use, energy consumption and social responsibility). Within materials, strong emphasis is given to the toxicity of the substances that make up the product. This evaluation should include the identification of all elements present in a concentration higher than $100 \mathrm{ppm}$ (parts per million), as well as their characterization in terms of impacts to human and environmental health. In addition, substances that are considered bio-accumulative or toxic (such as organohalogens or heavy metals, for instance) are classified as "red" and slated for substitution.

In addition to toxicity, the unsustainable rate of consumption of several natural resources is also a topic of great concern. Therefore, reutilization of materials has been also gaining more and more importance. In this regard, the materials used should be classified into recyclable, compostable or rapidly renewable, and the most appropriate cycle for reutilization (technical or biological) should be clearly defined.

It has been observed that most green product development initiatives do begin with the characterization of materials used and evaluation of their environmental impact; however, this information usually is not available to end-users. In fact, consumers have no information about environmental impacts even for the most commonly used materials, such as plastics.

In this scenario, the information disclosure practices adopted by the product manufacturer are considered to be of paramount relevance. Just like it already happens with food products, consumers have the right to know which "ingredients" or which substances are present in all products they buy. Furthermore, only by having access to this kind of information can the end-user understand their impact and make informed decisions about which products to buy.

In the same way, users should be well oriented and perhaps even incentivized to help closing the loop by returning the product after its service life to the company (through a product take-back system) or to nature by composting it. 


\section{The footwear industry}

Nowadays the footwear industry has characteristics that are similar to many other sectors (e.g. global reach, large economic and environmental impact, centralized manufacturing, complex supply chain and distribution networks) [9].

\subsection{The environmental impact of footwear industry}

In footwear products, as in other cases, materials production and manufacturing typically account for a very large share of the overall environmental impact associated with the products, and challenges remain in how to achieve better environmental performance using only the available non-toxic materials coming from renewable and/or recycled sources.

The usage phase is typically of less concern in terms of environmental impact, and the product service life can vary considerably depending on the specific type of footwear [2].

Another area that has demanded considerable attention is the treatment of animal skins and hides to make leather, a chromium-based process called tanning. Aiming to limit environmental impact due to the high toxicity of chromium, some footwear companies have collaborated with the BLC Leather Working Group and adopted rigid production, treatment and control practices. The use of natural fibers such as organic cotton, flax, hemp silk, cork, wool and cashmere has also been also highlighted by the footwear companies with environmental initiatives. Among recycled materials, recycled polyester is typically a favored option among the companies, although its use remains relatively small as compared to virgin polyester. The use of both virgin and recycled polyester, however, has been criticized to the presence of toxic elements, and an alternative socalled Eco-Intelligent Polyester has been proposed [10].

The use of water-based adhesives, primers and solvents reduces considerably the toxicity of the product assembling process, and has been hailed as an important advance in recent years, together with the investigation and increased use of green and natural rubbers.

None of the companies cited in this work own the manufacturing process, so they must develop partnerships with suppliers in order to achieve the intended results, starting with a deep understanding of materials flow and the organization of their global supply chain. For that reason, one of the main initiatives has been to analyze the whole production chain from raw material production to product distribution, using tools such as life cycle assessment and mapping the environmental footprint of their products. The environmental indicators used in this process and reported by the companies are similar to those highlighted in the cradle to cradle design concept, including the analysis of material toxicity (restricted substance list) and selection, water use, energy consumption and generation of residues.

Although this study focuses on the footwear industry, the work is not necessarily limited to one industrial sector. Many modern global companies have important characteristics in common, and the theoretical concepts discussed here apply to product development and production processes in general.

\subsection{Social responsibility in the footwear industry}

With regards to social responsibility, the historical analysis of the footwear industry shows that the sector, similarly to others, has continuously moved in search of cheaper labor costs. However, nowadays companies have adopted more and more rigorous codes of conduct that guide their relationship with contracted factories, but success may depend basically on their ability to supervise working conditions.

The choice of outsourcing manufacturing to countries with lower labor costs can lead to the inadvertent selection of suppliers who adopt inadequate standards regarding working conditions. In addition, the outsourced manufacturing system ends up transferring the environmental impacts related to production to countries other than those generating the demand and actually using the products made. An argument commonly used in favor of large companies or brands is that it's not clear to which extent the business can be made responsible for the actions of sub-contracted factories, which operate under cultural norms and social needs specific to a given country [11].

Such open questions often arise in current debates about sustainability, from a social and environmental perspective, in organizations that have built a globalized structure. At the same time, it is a fact that reports associating specific brands and products to bad work conditions can seriously damage a company's reputation and decrease sales. As a consequence, companies have been very careful when choosing suppliers and establishing ethics codes that must be followed by the contracted factories, in addition to 
seeking certifications and partnerships with organizations such as the Fair Labor Association (FLA).

Regarding the precautionary principle, described earlier, in the footwear industry its implementation can be related mainly to (i) selection and production of materials and components, (ii) control of manufacturing and waste generation, and (iii) planning of the end-of-life of products. In this area, excluding a few cases, so far little has been done to reduce the problems associated to the use of hazardous materials. Also, post-consumption waste generation is currently not considered a problem for the industry, since the final destination of worn footwear is typically municipal landfills paid for by the tax payer.

In the next section, the case studies illustrate the initiatives carried out by three American companies that have been pioneers in the development of more environmentally-friendly footwear products, focusing specifically on their efforts regarding their material composition disclosure practices.

\section{Case Studies}

This work has focused on the analysis of the product development process, and advances made so far, by three companies that have worked towards reducing the environmental impact of their footwear products.

American footwear companies presently design, develop, market and sell products under their own brand while sub-contracting manufacturing abroad. Efforts are directed at innovation and some companies have invested more and more in the development of more environmentally-friendly product lines, partly responding to outside pressures and partly due to a fast-growing market for green products

The examples of a large company (Nike), a medium (Patagonia) and a small company (Simple Shoes) are illustrated here. American footwear companies presently design, develop, market and sell products under their own brand while sub-contracting manufacturing abroad. Efforts are directed at innovation and some companies have invested more and more in the development of more environmentallyfriendly product lines, partly responding to outside pressures and partly due to a fast-growing market for green products.

\subsection{Patagonia}

Patagonia, a medium-sized company founded in 1972, which produces mostly apparel for outdoor activities, currently lists environmental indicators (energy consumption, water use, distance travelled, $\mathrm{CO}_{2}$ emissions and waste generated) for 17 apparel items produced by the company, including one pair of shoes [12].

The company organized its actions based on the concept of ecological footprint, and it has been examining its products over the whole supply chain. The objective is to analyze current practices and investigate possible improvements, which could be implemented at industrial scale and lead to better results. The tool, published in the company's website, is referred to as "Footprint Chronicles" (figure 1). In addition to the environmental indicators selected, the interface follows the product's supply chain, showing each step along the way though maps, text data, pictures and videos.

The metrics used - (i) energy consumption, (ii) $\mathrm{CO}_{2}$ emissions, (iii) waste generation and (iv) water use - define the product evaluation criteria over its life cycle, which begins at the origin of the main materials used (for example, from the fields where cotton is planted, in the case of natural fibers, or the cattle farms, in the case of leather, or even the production of polymers, in the case of synthetic materials), and follows the path travelled by the product until it reaches the company's distribution center in Reno, Nevada. According to Patagonia, the ecological footprint tool makes it possible to map the supply chain and better manage it.

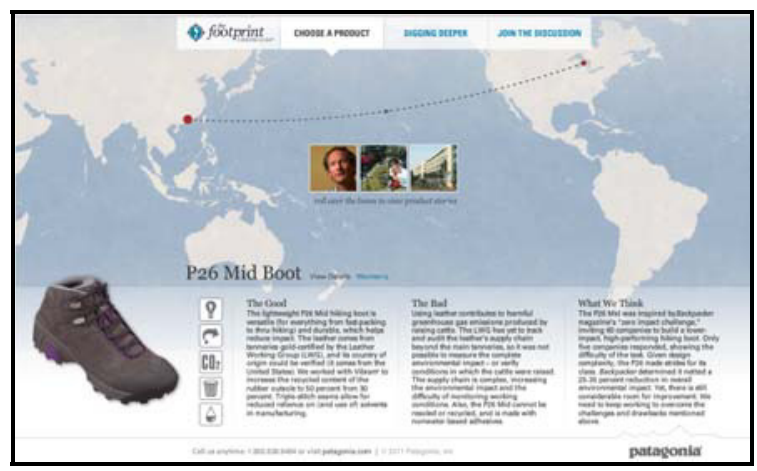

Figure 1 - Footprint Chronicles by Patagonia (Source: www.patagonia.com)

Besides that, the company notes that several types of materials and components are used to make each 
piece of garment. As a consequence, their analysis has focused mostly on the main materials used. Secondary materials such as buttons and zippers can also be evaluated when these elements add up to a significant portion of the product. The Company even mentions that the manufacturing process is surprisingly dirty, due to the use of chemicals, oils and a considerable amount of natural resources.

\subsection{Simple shoes}

Simple Shoes illustrate a group of smaller companies whose core business rely on the development and marketing of green products. The company began production in 1991 and its reported goal is to make products " $100 \%$ sustainable" [13].

Simple Shoes, while not having a similar design tool, has made available online the complete lifecycle assessment, supply chain analysis and end-oflife evaluation for four of its products [14].

After setting its goal of being sustainable, the company began its pursuit for environmentallyfriendly materials and processes, and in 2008 it established a partnership with the Donald Bren School of Environmental Science and Management at the University of California, Santa Barbara. Up until then, the company aimed at being "green" but didn't have quantitative data to back up and orient its efforts. The research led to a detailed life-cycle assessment (LCA) of four of its products, two of which belonged to the company's more environmentally-friendly line, one intermediate (said to be "green") and one product considered conventional. The results of the study shed light on the environmental impact of the materials used, and also included a discussion about endof-life alternatives. One limitation, however, is that the name of the products analyzed was not included in the text. Anyhow, the UC Santa Barbara report highlighted that, in the case of Simple Shoes, about $90 \%$ of the environmental impact came from the production of materials and manufacturing. Transportation of the finished product did not have a major impact, even though the company has its products manufactured in China, in the city of Guangzhou.

As illustrated by figure 2 , the company presents a detailed description of the materials used in each product alongside the product presentation in its website, although quantitative environmental indicators or metrics are not presented.

The company states that in its environmentallyfriendly line of products, it includes only "natural" materials, i.e., renewable materials (such as organic cotton, jute, hemp, bamboo and natural rubber) on the top part of the shoes, and recycled materials (such as PET and used tires) on the sole. In this product line, toxic solvent-based adhesives were replaced by water-based alternatives.

More recently, the company also introduced footwear products with biodegradable soles, which could become an interesting solution to the end-oflife problems typically associated with shoes.

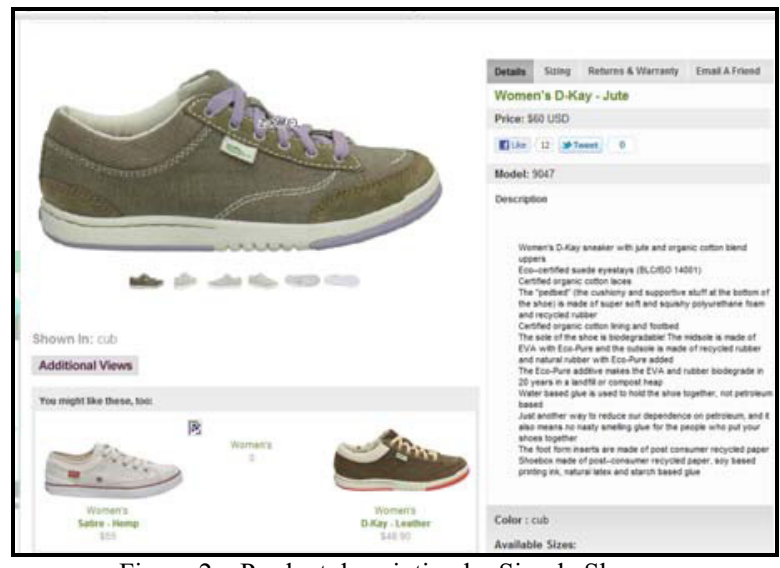

Figure 2 - Product description by Simple Shoes (Source: www.simpleshoes.com)

\subsection{Nike}

There is a key group of large and medium companies that were founded decades ago and that are now undergoing a transition from traditional and wellestablished production practices into the development and introduction of more environmentally-friendly product lines. Among this group, Nike is a prime example. Founded in 1964 (then called Blue Ribbon Sports, BLS) Nike is today the global leader in athletic shoes, with annual revenues exceeding \$19 billion. In 2005, the company introduced the Considered product line, a selection of more environmentally-friendly products that has been greatly expanded since then [15].

A version of the Considered Index, a proprietary online tool developed by Nike to predict environmental footprint and aid product design and development inside the company (and which takes into consideration key impacts such as solvent use, waste, materials, energy and water), is set to become publicly available through the new Creative Commons-based GreenXchange program [16]. In 2010, the design tool developed for apparel evaluation was made available to 
the public, and a similar footwear design tool is expected to be released in the near future.

Nike products whose score is significantly better than the corporate average in this Index are designated Considered by the company [17]. However, at this moment no information about the materials used in each product is provided. Similarly, product scores in the Considered Index are used only internally by the company, and currently are not made available to the general public.

\section{Final comments}

To achieve products that can be referred to as sustainable, it is fundamental to promote conceptual changes in the product development process as a whole, encouraging innovative solutions in product design as well as production. Change is not easy, however, and several steps can act as barriers along the way, including for example: technological limitations; the manner production is organized; how distribution, sale and delivery are made; how the product is used and discarded by the consumers; among others. We believe it is paramount for companies to establish ambitious future goals that build on top of current practices and initiatives in order to recognize and deal with such limitations appropriately.

Product end-of-life issues are crucial barriers to be overcome in the evolution towards a closed-loop and cyclic production. These involve not only material reprocessing techniques but also partnerships with suppliers, interest and availability of companies (to establish take-back networks), and, perhaps primarily, consumer cooperation. End users play a key role because they will determine the endof-life, as the period between purchase and return after use. Returning apparel items after use for recycling is not a common practice, and take-back initiatives in this area have met only limited success, indicating that an incentives structure could be put in place to encourage consumer participation.

Naturally, the difference in core business influences both the product design and expected performance in use, in addition to the image associated with the product. Professional running shoes serve a different need than casual day-to-day shoes, for instance. In the case of Nike, the core business is to produce high-performance athletic shoes, and the challenge for the company is to seamlessly integrate sustainability into its product line (and image) without decreasing performance. On the other hand, the list of constraints and requirements is quite different in the case of a company like Simple Shoes, whose primary business is to produce, market and sell casual shoes that are as environmentally-friendly as possible. However, despite such differences, it can be observed that, in a first moment, the sustainable product development initiatives carried out by both companies have important similarities.

Regarding social responsibility, the three companies illustrated here have established Codes of Conduct that all contracted factories are supposed to adhere to. Nike and Patagonia disclose the list of contracted factories and are also members of the Fair Labor Association (FLA), while Simple Shoes is currently seeking FLA accreditation.

Finally, in spite of outsourcing production, it can be observed that American companies have invested a great deal in design and innovation over the years, and more recently on pioneering sustainable product development initiatives. Several challenges remain to be resolved in order to ultimately close production loops and advance closer to an ideal cradle to cradle concept of production, although long-term goals related to biological and technical metabolisms are already being discussed within product design teams.

\section{Acknowledgements}

We gratefully acknowledge the industry professionals who have contributed with their knowledge and experience to this project. The feedback and insight provided by colleagues at the Berkeley Energy and Sustainable Technologies (BEST) Lab and the Laboratório de Otimização de Produtos e Processos (LOPP-UFRGS) are also sincerely appreciated.

\section{References}

[1] Staikos, T. Rahimifard, S. (2007) Post-Consumer Waste Management Issues in the Footwear Industry, Journal of Engineering Manufacture, v.221, n.2.

[2] Albers, K.; Canepa, P. Miller, J. (2008) Analyzing the Environmental Impacts of Simple Shoes - A Life Cycle Assessment of the Supply Chain and Evaluation of End-of-Life Management Options, University of California Santa Barbara

[3] American Apperal \& Footwear Association (2007). Trends An Annual Compilation of Statistical Information on the U.S. Apparel \& Footwear Industries. Arlington, VA. Available at: http://www.apparelandfootwear.org/Statistics.asp.

[4] McDonough, W. Braungart, M. (2002) Cradle to cradle: remaking the way we make things. New York: North Point Press. 
[5] Van Der Ryn, S. Cowan, S. (1996). Ecological design. Washington, D.C.: Island Press.

[6] U.N. Global Compact.(2009) United Nations Global Compact. Disponível em: http://www.unglobalcompact.org/. Acesso em: 12/06/2009.

[7] Harremoës, P., D. Gee, et al.(2002) Late lessons from early warnings: the precautionary principle 1896-2000. European Environment Agency. Luxembourg.

[8] Jacques, J. Estudo de Iniciativas em Desenvolvimento Sustentável de Produtos em Empresas Calçadistas a partir do Conceito Berço ao Berço. Ph.D. Dissertation, Universidade Federal do Rio Grande do Sul, Brasil.

[9] Gereffi, G. (2008). The Global Economy: Organization, Governance, and Development. In: Lechner, F. J.Boli, J. (Ed.). The globalization reader. Malden, MA: Blackwell Pub, The Global Economy: Organization, Governance, and Development.

[10] McDonough, W. Braungart, M. (2002) Transforming the Textile Industry. Available at: http://www.mcdonough.com/writings/transforming_textile.ht $\mathrm{m}$

[11] Locke, R. M. e A. J. Siteman. The Promise and Perils of Globalization: The Case of Nike. In: T. A. Kochan e R.L.Schmalensee (Ed.). Management: Inventing and Delivering Its Future. Cambridge, MA: The MIT Press, p.39-70, 2003.
[12] Patagonia (2010). The Footprint Chronicles. Available at: http://www.patagonia.com/web/us/footprint/index.jsp. Access on: $02 / 05 / 2010$.

[13] Simple Shoes Website (2009). Available at:. http://www.simpleshoes.com. Access on: 07/10/2009.

[14] Albers, K.; Canepa, P. Miller, J. (2008) Analyzing the Environmental Impacts of Simple Shoes - A Life Cycle Assessment of the Supply Chain and Evaluation of End-ofLife Management Options. Donald Bren School of EnvironmentalScience and Management, University of Santa Barbara, Santa Barbara

[15] Nike, Inc. (2009) Nike's Considered Design Products Redefining Performance and Sustainability. Available at: http://www.nikebiz.com/responsibility/. Access 04/22/2009.

[16] Nike, Inc. (2010). Organizations Call for Greater Open Innovation to Advance Sustainability. Available at: http://www.nikebiz.com/media/pr/2010/01/27_GreenXchang e.html. Access on: 02/05/2010.

[17] Nike, Inc. (2010). Corporate Responsibility Report. Available Access on: 02/05/2010. 